\title{
Weapons Used to Harm Female Victims of Intimate Partner Violence and Community Violence
}

\author{
Maria Ulnes $1^{*} \bigotimes(D)$, Hanna Hultquist ${ }^{1}$, Manjika M Sithum ${ }^{2}$, Muditha Vidanapathirana ${ }^{3}$, \\ Kumudu Wijewardene ${ }^{2}$, Lena Anderson ${ }^{4}$ \\ ${ }^{1}$ Faculty of Medicine, University of Gothenburg, Sweden, \\ ${ }^{2}$ Department of Community Medicine, Faculty of Medical Sciences, University of Sri \\ Jayewardenepura, Sri Lanka \\ ${ }^{3}$ Department of Forensic Medicine, Faculty of Medical Sciences, University of Sri \\ Jayewardenepura, Sri Lanka \\ ${ }^{4}$ Department of Community Medicine and Public Health, the Sahlgrenska Academy, Sweden.
}

\section{Introduction}

The pattern of intimate partner violence has not been studied in-depth in Sri Lanka. The aim of this study was to investigate the weapons use among women exposed to intimate partner violence (IPV) and to compare with community violence $(\mathrm{CV})$.

Method

A retrospective, comparative cross-sectional study of women who have undergone medico-legal examination after reporting IPV or CV to a tertiary care hospital, in Colombo, Sri Lanka years from January 2011 to December 2012 was conducted. Of 9000 Medico-Legal Examination Forms, women above 18 years who had reported IPV and $\mathrm{CV}$ were studied.

\section{Results}

The prevalence of reported cases of IPV was 2.8\% and CV was 5\%. Of them, 255 (36\%) IPV and 449 (64\%) CV were reported. IPV was common among young, married, unemployed women $(p<0.05)$. The most common weapon was the wooden bar $(n=91,13 \%)$. Alcohol is a significant factor $(\mathrm{p}<0.05)$ but the use of 'weapons' was not significantly associated $(\mathrm{p}>0.05)$. Assault with a weapon was common at home in the morning and resulted in severe injuries $(\mathrm{p}<0.05)$. CV occurred outside home by multiple, known perpetrators and the known perpetrators used 'occasional weapons' and unknown perpetrators used weapons $(\mathrm{p}<0.05)$.

\section{Conclusions}

Women exposed to IPV were young, married and unemployed. Most assaults were due to manhandling while sexual violence reports were fewer than expected. Weapon assaults are common at home in the morning and result in severe injuries but not associated with alcohol abuse. There were many similarities between IPV and CV assaults which indicate that both groups take their basis in a gender-unequal society that breeds violence. The victim knew the abuser, not only in the IPV group as expected but also in the CV group. CV occurs outside the home by known perpetrators using 'occasional weapons'. CV in Sri Lanka and worldwide is an almost unexplored area that needs to be further investigated in order to develop evidence-based intervention programmes.

Keywords: Gender-based violence, Intimate partner violence, Community violence, Sexual violence, Weapons, Sri Lanka.

Copyright: @ 2017 with the Medico-legal Journal of Sri Lanka.

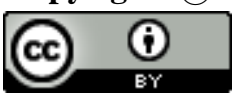

This is an open-access article distributed under the terms of the Creative Commons Attribution 4.0 International License, which permits unrestricted use, distribution and reproduction in any medium provided the original author and source are credited

Funding: None

Competing interests: None

Received: 02 April $2018 \quad$ Accepted revised version: 30 May 2018 Published: 30 June 2018

*Corresponding author: Faculty of Medicine, University of Gothenburg, Sweden. Tel: +46709700872, E-mail address: mariaulnes@hotmail.com, $\varangle$ (D) https://orcid.org/0000-0001-8807-2188

Cite this article as: Ulnes M, Hultquist H, Manjika MS, Vidanapathirana M, Wijewardene K, Anderson L. Weapons used to harm female victims of intimate partner violence and community violence. Medico-Legal Journal of Sri Lanka, 2018; 6(1):17-21

DOI: http://dx.doi.org/10.4038/mljsl.v6i1.7367 


\section{Introduction}

Intimate partner violence (IPV) refers to acts of physical, emotional and sexual abuse within current or former intimate relationship, co-habiting or not. ${ }^{[1]}$ IPV should be considered seriously because it is accountable for $40-70 \%$ of the female murders. ${ }^{[2]}$ It shows patriarchal dominance and is commonly committed by men. ${ }^{[3]}$ WHO describes two subcategories of interpersonal violence: Intimate partner violence (IPV) and Community violence (CV). ${ }^{[4]}$

A wide range of objects is used as weapons against intimate partners. According to a study done in Sri Lanka, 1980, most of the women had been threatened with some kind of weapon that would be found at home and the husbands had a problem with alcohol abuse or heavy drinking. ${ }^{[5]}$ However, in developed countries such as the USA, the use of firearms in intimate partner violence (IPV) is widely recognized as an important public health threat. ${ }^{[6]}$ Further, the firearms, especially handguns, are more common in the homes of battered women than in households in the general population in the USA. ${ }^{[7]}$

This study was done to describe types of weapon and injuries in women reported with IPV compared to that of women reported with $\mathrm{CV}$ at a tertiary care hospital, in Colombo, Sri Lanka. An additional aim was to describe socioeconomic factors, perpetrators and factors related to crime.

\section{Methods}

This comparative, descriptive, cross-sectional study was conducted at an Office of the Judicial Medical Officer, tertiary care hospital, in Colombo. All (9000) Medico-legal examination forms (MLEFs) of victims reported as Violence against women (VAW) comprising of Intimate partner violence (IPV) and Community violence (CV)over two years from January $1^{\text {st }}, 2011$ to December $31^{\text {st }} 2012$ were studied using a data collection form. These documents were belonged to 8 consented Forensic Medical Officers out of 12 who were working at that unit.

Women above 18 years with physical/sexual violence, where the perpetrator was partner/spouse whether cohabiting/not, were considered as IPV.

Women above 18 years with physical/sexual violence, where the perpetrator was not a family member or partner were considered as CV. Fatal cases and who were abused by other family members were excluded.

To define cases of sexual violence WHO's definition of Sexual Violence ${ }^{2}$ was used and all women who reported having experienced any sexual act, comments or advances were included. The SPSS version 19was used to calculate frequencies, presented as proportions and percentages. $\mathrm{Chi}^{2}$ tests were performed on bivariate tests and p-value $<0.05$ was considered statistically significant. Ethical clearance was obtained from the University of Sri Jayewardenepura. Further, permission was obtained from Director General of Health Services, Sri Lanka and Director, Teaching Hospital Colombo South.

\section{Results}

Out of 9000 MLEFs, 704 were found as Violence against women (VAW) and the prevalence of reported cases of IPV was $2.8 \%$ and $\mathrm{CV}$ was $5 \%$. Of the violence against women cases, 36\% (255) were IPV and 64\% (449) were CV.

In VAW, ages ranged from 18-90 years. Most occurred in the age group 26-35 years $(33 \%, n=236)$. In VAW, 88\% (462) were married, 9\% (50) were unmarried, 2\% (12) were divorced/separated and 02 were living together.

In VAW, the time of the abuse was mainly (41\%, $\mathrm{n}=287$ ) in the evening. No incidents found after midnight. The body parts $(56 \%, \mathrm{n}=394)$ were commonly used to assault. 'Occasional weapon' was used by $36 \%(n=255)$ and the types were wooden bars $(\mathrm{n}=91,13 \%)$, brooms, chairs etc. (Figure 1). 'Weapons' were used by $08 \%(n=55)$ and the types were knives (46) swards (05) and guns (04).

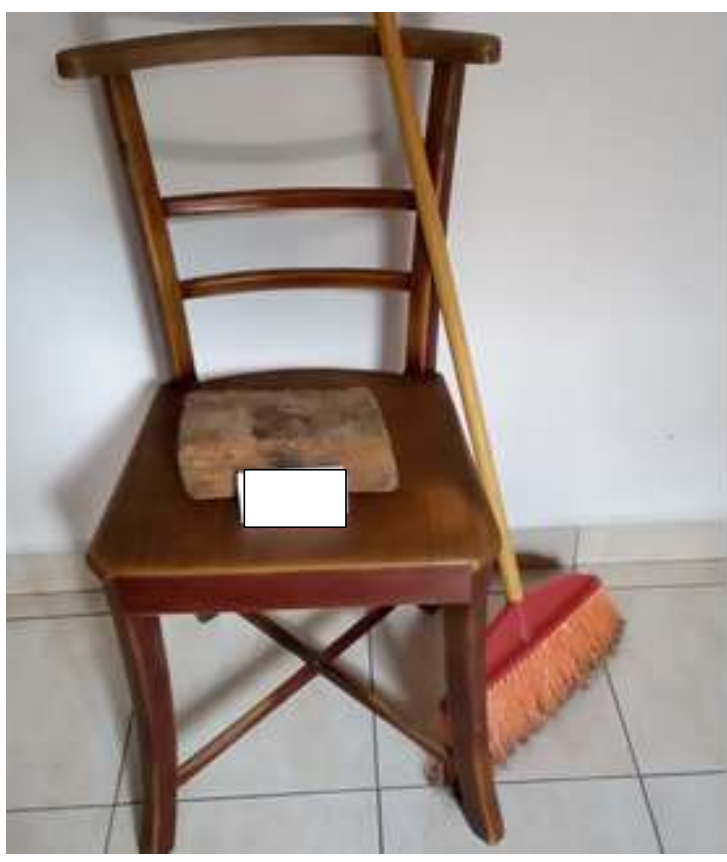

Figure 1. 'Occasional weapons' found in a case 
In VAW, Blunt force was used in $89 \%(\mathrm{n}=628)$ and sharp force in $9 \%(n=64)$ while $2 \%(n=09)$ sustained burns, chemical injuries, firearm injuries and ruptured eardrums.

Age distribution of IPV and CV are shown in Table 1. Fifty-nine percent (59\%) of IPV and $41 \%$ of CV occurred in below 35 years group, and this difference was statistically significant $\left(\chi^{2}=16.796, \quad \mathrm{df}=1\right.$, $\mathrm{p}=0.000)$.

Table 1. Distribution of age

\begin{tabular}{|c|c|c|}
\hline Age group & $\begin{array}{r}\text { IPV } \\
(\mathrm{N}=255) \\
\mathrm{n}(\%)\end{array}$ & $\begin{array}{r}\mathrm{CV} \\
(\mathrm{N}=449) \\
\mathrm{n}(\%)\end{array}$ \\
\hline$=<25$ years & $46(18 \%)$ & $60(12 \%)$ \\
\hline 26-35 years & $104(41 \%)$ & $132(29 \%)$ \\
\hline $36-45$ years & $68(27 \%)$ & $97(22 \%)$ \\
\hline 46-55 years & $32(11 \%)$ & $81(18 \%)$ \\
\hline 56-65 years & $04(02 \%)$ & $43(11 \%)$ \\
\hline $66-75$ years & $01(01 \%)$ & $29(06 \%)$ \\
\hline 76-85 years & $00(00 \%)$ & $05(01 \%)$ \\
\hline$>85$ years & $00(00 \%)$ & $02(01 \%)$ \\
\hline
\end{tabular}

Sixty-eight percent (173) of IPV and 48\% (215) of CV group were unemployed and this difference was significant $\left(\chi^{2}=18.097, \mathrm{df}=1, \mathrm{p}=0.000<0.01\right)$. Ninety four percent (240) of IPV and $82 \%(n=368)$ of CV were married and this difference was significant $\left(\chi^{2}=18.067, \mathrm{df}=1, \mathrm{p}=0.000<0.01\right)$.

Eighty-three percent (211) of IPV and $40 \%(n=180)$ of CV were abused in their homes and this difference was significant $\left(\chi^{2}=98.507, \mathrm{df}=1, \mathrm{p}=0.000<0.01\right)$. Multiple perpetrators were more common in CV $(33 \%)$ when compared to $2.8 \%$ of IPV and this difference was statistically significant $\quad\left(\chi^{2}=86.264, \quad \mathrm{df}=1\right.$, $\mathrm{p}=0.000<0.01)$.

Body parts such as hand or feet were used by $61 \%$ of IPV and $53 \%$ of CV. Types of instrument used by IPV and $\mathrm{CV}$ are shown in Table 2.

Table 2. Type of instrument used in IPV and CV

\begin{tabular}{lrr}
\hline Instrument type & $\begin{array}{r}\text { IPV } \\
(\mathbf{N}=\mathbf{2 5 5})\end{array}$ & $\begin{array}{r}\mathbf{C V} \\
(\mathbf{N}=\mathbf{4 4 9}) \\
\mathbf{n}(\%)\end{array}$ \\
\hline nody part & $155(61 \%)$ & $239(53 \%)$ \\
Occasional weapon & $86(34 \%)$ & $169(38 \%)$ \\
Weapon (knives/guns) & $14(05 \%)$ & $41(09 \%)$ \\
\hline
\end{tabular}

In both IPV and CV, the most common object was a wooden bar (IPV $=11 \%$ and CV 14\%) and Table 3 shows the objects that were most commonly used.
Table 3. List of most commonly used objects in IPV and CV (body parts excluded)

\begin{tabular}{llll}
\hline IPV & n (\%) & CV & n (\%) \\
\hline Wooden bar & $28(11 \%)$ & Wooden bar & $63(14 \%)$ \\
Knife/sward & $14(06 \%)$ & Knife/Sword & $37(08 \%)$ \\
Broomstick & $13(05 \%)$ & Iron bar/tool & $19(04 \%)$ \\
Ironbar/tools & $07(03 \%)$ & Broomstick & $15(03 \%)$ \\
Scissors & $03(01 \%)$ & Bottle & $08(02 \%)$ \\
Stone & $03(01 \%)$ & Firearm & $04(01 \%)$ \\
\hline
\end{tabular}

In IPV, 'Some kind of weapon' (occasional weapons and knives or guns) was used in $58 \%$ of morning incidents (6 am to 12 noon) and $38 \%$ of after-hours incidents and this difference was significant $\left(\chi^{2}=5.5\right.$, $\mathrm{df}=1, \mathrm{p}=0.018<0.05)$. 'Some kind of weapon' was used in $22 \%$ (20) of outside incidents and $45 \%$ (80) of home incidents and this difference too was significant $\left(\chi^{2}=6.891, \quad \mathrm{df}=1, \mathrm{p}=0.009<0.01\right)$. There was no significant association with age, marital status, having children, place of residence, number of perpetrators or age difference within a couple with 'Some kind of weapon use' ( $p>0.05)$.

In IPV, severe injuries (grievous or more) were found in $24 \%(n=24)$ of incidents that used 'some kind of weapon' and $8 \%(n=11)$ of incidents that used 'body parts' and this difference was significant $\left(\chi^{2}=12.456\right.$, $\mathrm{df}=1, \mathrm{p}=0.000<0.01)$.

In $\mathrm{CV}$, use of weapon (guns/ knives) was found in $21 \%$ $(n=21)$ of unknown perpetrators and $6 \%(n=20)$ of known perpetrators and this difference was significant $\left(\chi^{2}=15.089, \mathrm{df}=1, \mathrm{p}=0.000<0.01\right)$.

The type of force (blunt or sharp) did not significantly associate among IPV and CV groups $(p=0.357>0.05)$.

Eighty-nine percent $(n=82)$ of IPV and $11 \%(n=10)$ of $\mathrm{CV}$ reported that perpetrators had alcohol-related problems. This difference was statistically significant $\left(\chi^{2}=128.240, \mathrm{df}=1, \mathrm{p}=0.000<0.01\right)$. But alcoholrelated problems were not significantly associated with the use of weapon or severity of injuries $(p>0.05)$.

Sexual violence $(02 \%, \mathrm{n}=17)$ was reported in $05 \mathrm{IPV}$ and $12 \mathrm{CV}$ cases $(\mathrm{p}=0.538>0.05)$.

\section{Discussion}

The study is a review of forensic medical records of 704 women victims of intimate partner violence (IPV) and community violence (CV) in Sri Lanka. Reported cases of $\mathrm{CV}$ were more common than IPV and the frequency of $\mathrm{CV}$ was about 2 times higher than IPV. IPV lifetime prevalence in Sri Lanka has been 
estimated to $20-60 \%$ in $2011^{[8]}$ but the reported prevalence $2.8 \%$.

Cases of IPV and CV were similar in many ways: it was common that the assaults were carried out by a known person. Mainly used fists, and in a third of cases used some kind of weapon such as coconut scraper, brooms, furniture, iron bars etc. The most common instrument was a wooden bar $(11 \%$ in IPV and $14 \%$ in CV). Weapons such as knives ( $07 \%$ in IPV and $09 \%$ in CV) and guns ( $0 \%$ in IPV and $01 \%$ in CV) were rarely used. The similarities in both groups can be interpreted as an indication that both groups took their basis in a gender-unequal society that breeds violence.

Most IPV victims were young and were dependent on a partner with economical and emotional bonds. ${ }^{[9]}$ Below 35 years of age was correlated to IPV, which matches previous research from the region but IPV women were slightly older compared to below 25 in the population survey by Jayasuriya et al. ${ }^{[10]}$ The women who were subjected to IPV were married to a higher extent and less often had an employment than CV women: a third of IPV victims had an employment- less than CV women but an increase in comparison to a 1980's case study of 60 "battered wives" where all were unemployed. ${ }^{[5]} \mathrm{IPV}$ is common among young, married and unemployed women $(\mathrm{p}<0.05)$.

There was a significant association between alcoholrelated problems and IPV $(\mathrm{p}<0.01)$ but the use of a weapon, the severity of injuries or site of injury was not significantly associated ( $>0.05)$. Out of the IPV women, $32 \%(n=82)$ reported that the perpetrator had an alcohol-related problem or alcohol abuse, compared to $80 \%$ in Saravanapavananthan's study from Jaffna (1982) ${ }^{[5]}$

In this study, fewer IPV women were assaulted with 'some kind of weapon' $(\mathrm{n}=100,39 \%)$ than the similar study done in 1982 where it was $60 \%{ }^{\left[{ }^{[5]} \text { ‘ }\right.}$ Some kind of weapon' was used in severe violence in IPV, in younger, married and unemployed women. These severe assaults were more likely to take place in the morning at victim's home $(\mathrm{p}<0.05)$. Women who reported domestic violence and especially those who reported partner used weapons tended to be more connected to their partner through the legal, emotional and economic ties.

When $\mathrm{CV}$ against women was considered, $\mathrm{CV}$ women were relatively older than IPV. Most of them were married, and $52 \%$ were employed. Similar to WHO definition, ${ }^{[4]}$ majority occurred outside the home, yet
$38 \%$ occurred in the victim's home. According to the WHO definition, most CV perpetrators are unknown people, but in this sample, majority knew their perpetrator, and weapons were used and more severe injuries occurred with an unknown perpetrator.

There were many similarities in use of weapon between the IPV and CV: In both groups, body parts were most commonly used to produce blunt force trauma and few used weapons such as knives or firearms, like in previous research ${ }^{[5,11]}$ The similarities suggest that a gender perspective can be applied; it is possible that the known perpetrator, tries to humiliate, scare and subordinate the victim. ${ }^{[12]}$

Victims of IPV had common traits that might make them more dependent on their husbands (marital status, unemployment, uneducated), and these variables were even more commonly seen in women who were assaulted with weapons by their partners. The perpetrators were known to the victims and the use of a weapon was similar in both groups - blunt force violence with body parts or 'occasional weapon'. Therefore, risk assessment for women's physical and mental health and intervention programs for IPV need to be further explored and evaluated in an evidencebased way and put into a culturally competent context of Southeast Asia.

This study has used data that was scrutinized and judged by Forensic Medical Practitioners. This accounts for a high validity of definitions in the study. A large number of files were searched to identify statistically significant differences between the groups. The study had some weaknesses such as certain information were not available which decreased the statistical power especially regarding socioeconomic variables such as education, income etc. This study is limited to a sample of patients who have undergone medico-legal examination following reporting or as a referral.

In conclusion, most assaults were due to manhandling while sexual violence reports were fewer $(02 \%)$ than expected. 'Occasional weapon' assaults are common at home in the morning and result in severe injuries but not associated with alcohol abuse. CV occurs outside the home, by known perpetrators, using 'occasional weapons'. There were many similarities between IPV and $\mathrm{CV}$ assaults which indicate that both groups take their basis in a gender-unequal society that breeds violence. 


\section{Acknowledgements}

Nanayakkara R, Senior Lecturer, Department of Forensic Medicine, Faculty of Medical Sciences, University of Sri Jayewardenepura, Waduge PCLS, Karunanayake DSK, Ruchira ND, Sanjeewa HKR, Suffian H, Krizantha LP, Medical Officers, Office of the Judicial Medical Officer, Teaching Hospital, Colombo South for assisting in collection of data.

\section{References}

1. Guruge $\mathrm{S}$, Jayasuriya-Illesinghe V, Gunawardena $\mathrm{N}$, Perera J. Intimate partner violence in Sri Lanka: a scoping review. Ceylon Medical Journal. 2015; 60: 133-8.

DOI: http://doi.org/10.4038/cmj.v60i4.8100

2. SemahegnA, Mengistie B. Domestic violence against women and associated factors in Ethiopia; a systematic review. Reprod Health. 2015; 12: 78. PMCID: PMC4553009, PMID: 26319026, DOI:http://doi.org/10.1186/s12978-015-0072-1

3. Namy S, Carlson C, Hara K, Nakuti J, Bukuluki $P$, Lwanyaaga $J$ et al. Towards a feminist understanding of intersecting violence against women and children in the family. Social Science \& Medicine. 2017;184: 40-8. https://doi.org/10.1016/j.socscimed.2017.04.042

4. Krug EG, Dahlberg LL, Mercy JA, AB, \& Lozano R. World report on violence and health. Geneva, Switzerland: World Health Organization, 2002.

ISBN 9241545615

5. Saravanapavananthan, N., Wife battering: a study of sixty cases. Forensic Science International 1982; 20(2): 163-6.

DOI:http://doi.org/10.1016/0379-0738(82)90

141-4

6. April M. Zeoli M, Malinski R, Turchan B. Risks and Targeted Interventions: Firearms in Intimate Partner Violence. Epidemiol Rev 2016;38:125139.

DOI: http://doi.org/10.1093/epirev/mxv007

7. Sorenson SB, Wiebe DJ, Weapons in the Lives of Battered Women. Am J Public Health. 2004 August; 94(8): 1412-7.

PMCID: PMC1448464, PMID: 15284052

8. Perera, G, Gunawardene N, Jayasuriya V. Review of Research Evidence on Gender-based Violence
(GBV) in Sri Lanka, W.s.H. Committee, Editor, Sri Lanka Medical Association. 2011

ISBN: 978-955-9386-23-0

9. Capaldi DM, Knoble NB, Shortt JW, Kim HK. A Systematic Review of Risk Factors for Intimate Partner Violence. Partner Abuse. 2012 Apr; 3(2): 231-280.

PMCID: $\quad$ PMC3384540, NIHMSID: NIHMS385813, PMID: 22754606, DOI:http://doi.org/10.1891/1946-6560.3.2.231

10. Jayasuriya, V., K. Wijewardena, and P. Axemo, Intimate Partner Violence Against Women in the Capital Province of Sri Lanka: Prevalence, Risk Factors, and Help-Seeking. Violence Against Women 2011; 17(8): 1086-1102.

PMID: $21890530, \quad$ DOI: http://doi.org/10.1177/1077801211417151

11. Seifert D, Lambe A, Anders S, Pueschel K, Heinemann A. Quantitative analysis of victim demographics and injury characteristics at a metropolitan Medico-Legal Center. Forensic Science International 2009; 188(1-3): 46-51.

12. Krantz, G. and C. Garcia-Moreno, Violence against women. Journal of Epidemiology and Community Health 2005; 59(10): 818-21. DOI: http://dx.doi.org/10.1136/jech.2004.022756 